\title{
NUMERICAL STUDY ON THE OPTIMIZATION OF SMOKE VENTILATION IN A SITUATION OF A TRAIN FIRE AT A SUBWAY STATION
}

\author{
Khaled Mohamed Mohsen*, Hatem Mohamed Sadek**, and Mostafa Ahmed Ismail \\ Department of Mechanical Power Engineering, Faculty of Engineering - El-Mataria \\ Helwan University, Cairo, Egypt
}

\begin{abstract}
Smoke is the most deadly factor in the event of subway fire because it spreads in direction coincide with passenger's evacuation path. It reduces visibility and can cause deaths by suffocation (known as the silent killer). This paper presents a numerical study on the optimization of smoke ventilation mode at the conjunction area between the tunnel track and the platform in a situation of a train fire at a subway station. The present study investigates the effectiveness of smoke control or smoke ventilation utilizing an over track exhaust (OTE) fan. Fire dynamics simulator (FDS) program is utilized to simulate a subway car fire source with a steady heat release rate resulted from burning heptane as a fuel; the model dimensions are 150-m long, 22-m wide, and 19-m height. Calculations are based on the time of smoke spreading, people evacuation period, and the measurement of temperature by using distribution thermocouple along the station tunnel before and after applying the control. The results showed that, before applying the control, smoke filled the station, the vision became absent, and the smoke was expected to cause suffocation accompanied by death. After applying the control utilizing an OTE fan, smoke spreading was reduced, which suppressed the suffocation, and the visibility was clear improved during people evacuation.
\end{abstract}

\section{Introduction}

For the case of train fires on the subway stations, the operation of the smoke ventilation systems has to be studied in order to get optimal control of smoke propagation and provide better environmental conditions for personnel evacuation [1,2]. Fire dynamics simulator (FDS) developed by the NIST, as a popular computational fluid dynamic model for fire scenario simulation, is used to carry out a full-scale three-dimensional numerical simulation for the scenario that a train on fire stops beside the platform of a subway [3]. 


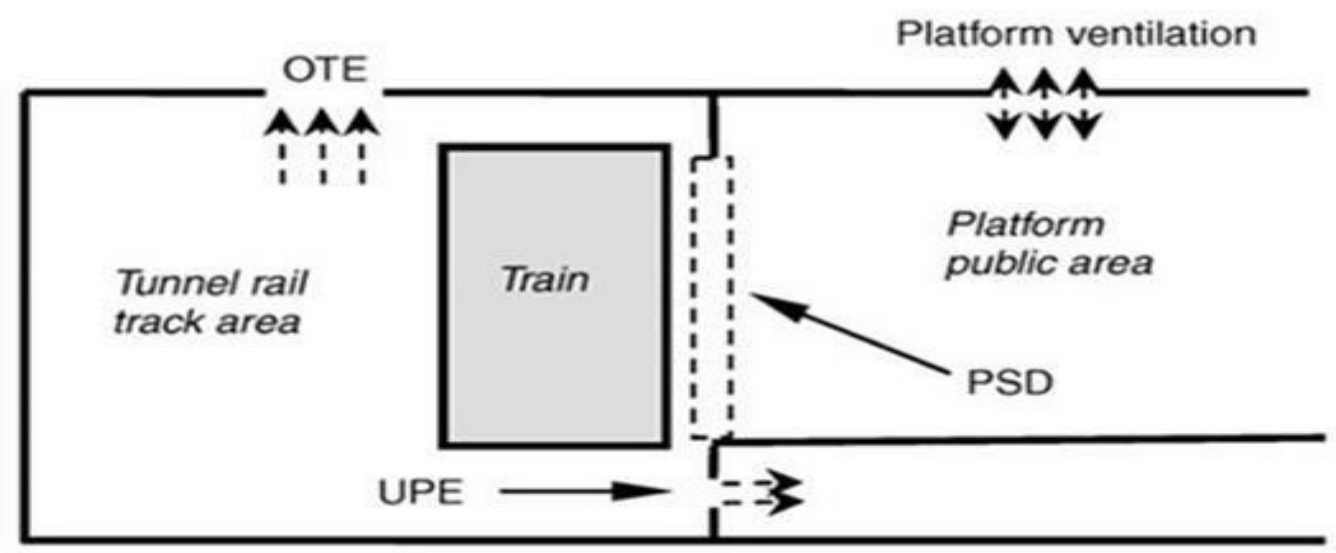

Figure (1) Schematic diagram of smoke exhaust systems when the fired train stops beside the platform.

As shown in Figure (1), tunnel rail track smoke exhaust system, over track exhaust (OTE) vents, and under platform exhaust (UPE) vents are distributed on the top and at the bottom of the tunnel respectively. The exhaust fan is shared by the OTE and UPE. Also, the ventilation system of the platform can be set as two patterns: smoke exhaust mode or air supply mode. The following engineering issues are demanded to be solved and the optimal cooperation mode of these systems is needed to be clarified such as:-

Some designers deem that when the train on fire stops at the platform, both UPE and OTE should be started together (UO mode) in order to achieve the best uniform effect of the smoke exhaust. However, some others believe that only starting the OTE system (OTE mode) will achieve better performance [4].

For the platform area, some designers deem that starting the air supply mode can create a pressurization effect to push the smoke flowing out from the train towards the platform back to the tunnel. However, some others deem completely different opinions that the platform smoke exhaust mode, which can extract smoke out of the platform, will be more effective[5].

Platform screen door (PSD) is usually constructed nowadays between the platform and the railway [6]. However, it is an extreme emergency that fire occurred in a subway train, in which case a train on fire is usually needed to be driven and stopped beside the platform. Under such a condition, the PSDs should be opened to ensure the evacuation of people from the train.

Figure (2) demonstrates the three-dimensional model for such a scenario. The subway platform is $21 \mathrm{~m}$ wide, $164.76 \mathrm{~m}$ long, and $6 \mathrm{~m}$ high. The size of the subway train model is $2.6 \mathrm{~m}$ wide, 140 $\mathrm{m}$ long, and $2.8 \mathrm{~m}$ high. Thirty PSDs are set up between the tunnel rail track area and the platform [7]. Every PSD is $1.8 \mathrm{~m}$ wide, $2.1 \mathrm{~m}$ high, and the total length of PSDs is $136.5 \mathrm{~m}$. A uniform grid system was used with a grid size of $0.3 \mathrm{~m}$ in the three spatial directions. The simulation volume is made of 1,072,000 cells. The fire source was set to be steady of $2 \mathrm{MW}$ in simulation, in the middle of the train.

As shown in Figure (3) the calculation results of temperature field allocations when the train on fire stops beside the platform under the UO mode (\#1) and the OTE mode (\#2). The comparison of temperature distributions shows that the temperature under the UO mode (\#1) is higher than that under the OTE mode (\#2) for most of the area, especially for the area near the fire source, where the temperature is over $60^{\circ} \mathrm{C}[8]$. 


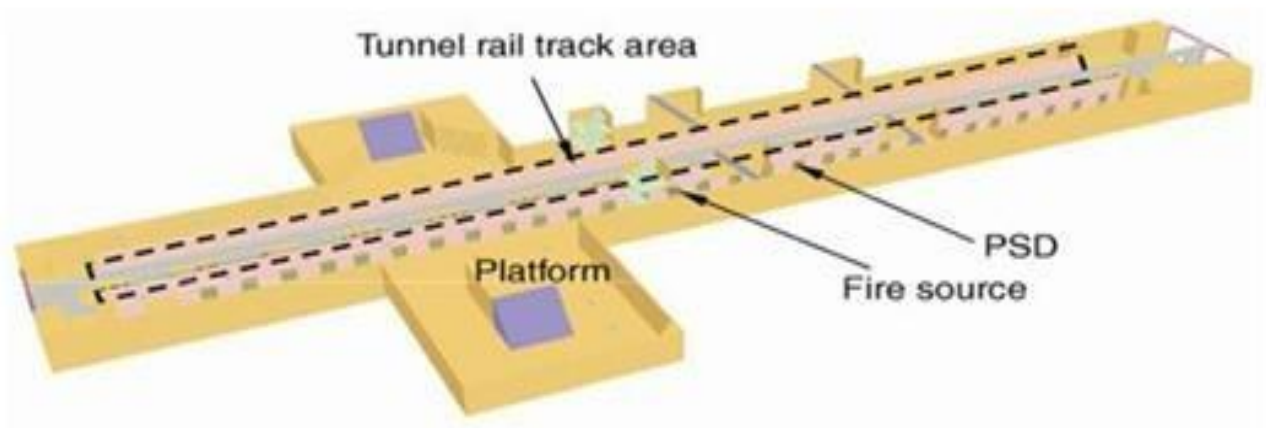

(a) Three-dimensional model

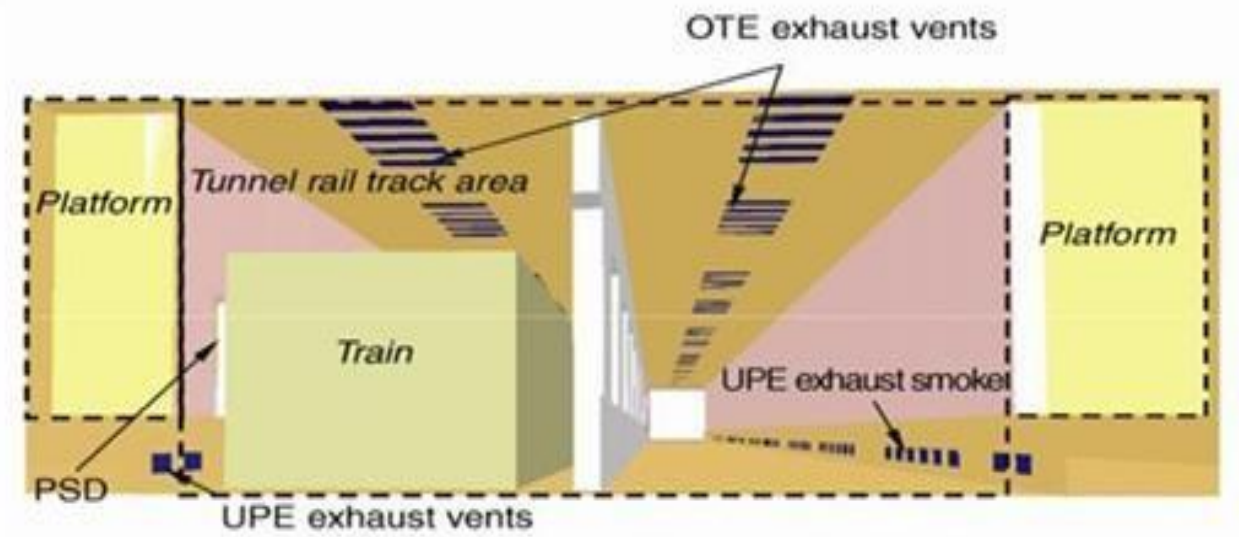

(b) Exhaust systems of the tunnel rail track area

Figure (2) Three-dimensional model of a train stopping beside the platform.
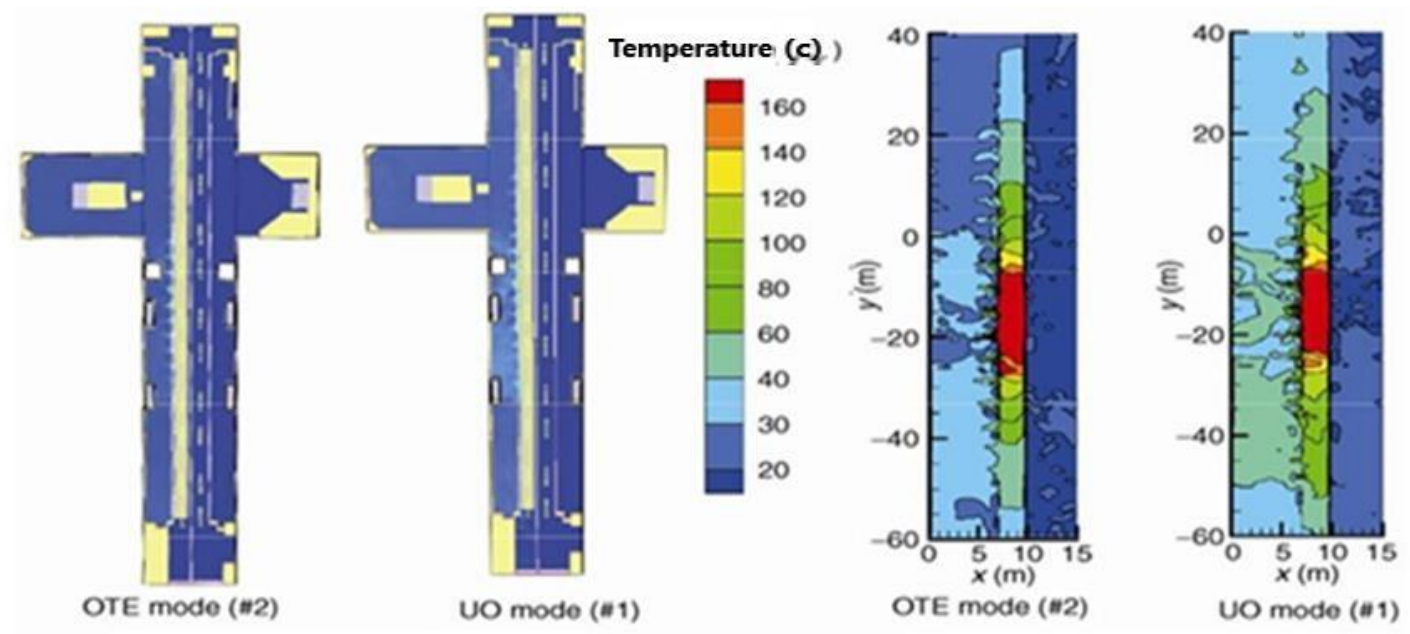

(a) Temperature field of $1.8 \mathrm{~m}$ height

(b) Temperature field near fire source

Figure (3) Comparison of temperature field of UO mode (\#1) and OTE mode (\#2) (at time of $900 \mathrm{~s}$ ) [8]. 


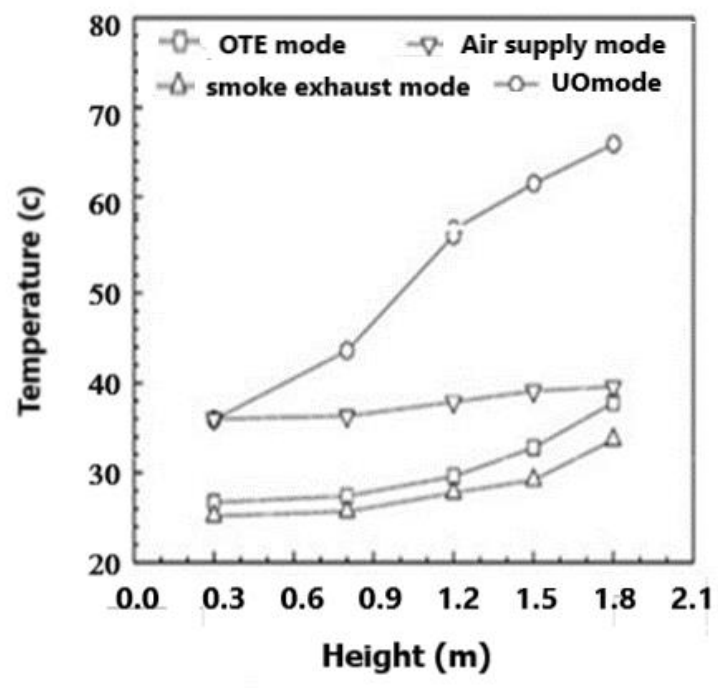

(a) Temperature at adiffrent height

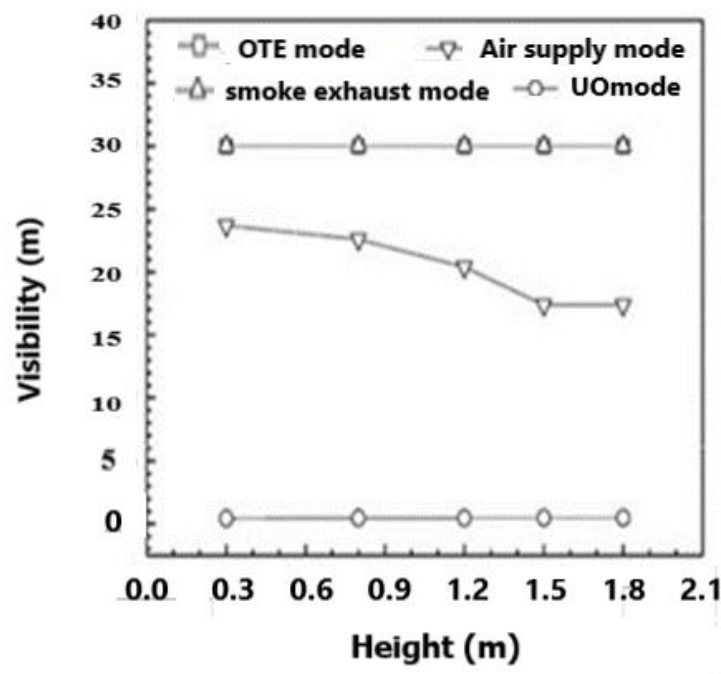

(b) Visibility at adiffrent height

Figure (4) Comparison of vertical profiles of temperature and visibility at the entrance of the upward stairway.

Figure (4) presents quantitatively the vertical profiles of temperature and visibility at the entrance of the upward stairway, which are critical points in the human evacuation route. It can be observed that the temperature is much higher, meanwhile, the visibility is lower, for the UO mode (\#1) and air supply mode (\#4) than those of OTE mode (\#2) and smoke exhaust mode (\#3). The temperature is the lowest, and visibility is the highest [9].

In case of a train on fire stopping beside the platform with the PSDs opened. Major findings and conclusions are:-

- The OTE mode takes advantage of the UO mode on either the lower temperature or better visibility at the characteristic height of $1.8 \mathrm{~m}$. The OTE mode should be advocated for tunnel rail track area under such a scenario.

- The extra air supply mode can make a lower temperature than that of the OTE mode only, but it cannot effectively push the smoke back to the tunnel area and even causes the worst visibility In comparison, starting platform smoke exhaust mode can make the lowest temperature and best visibility, which is helpful for evacuation.

\section{Fire scenarios Cairo metro at platform level}

In case of fire train at the platform as shown in Figure (5), the following scenario applied [10]:-

- Air conditioning equipment at the platform level is stopped.

- Smoke ventilation fans at other station' levels are operated in supply mode to avoid any smoke spreading from platform level to upper levels.

- Tunnel supply fans located at station' ends are stopped.

- Fans in the intermediate shaft are operated in a "push-pull" like mode (one side in supply mode while other is in exhaust mode).

- Depending on fire location along the platform (east or west side), the scenario above may be reversed by changing the operation of fans in intermediate shafts.

- Smoke curtains are installed at stairs from platform level to intermediate level to prevent smoke from spreading to the upper levels. 
- The efficiency of this scenario combined with smoke curtains has been fully demonstrated through simulations performed by the Contractor.

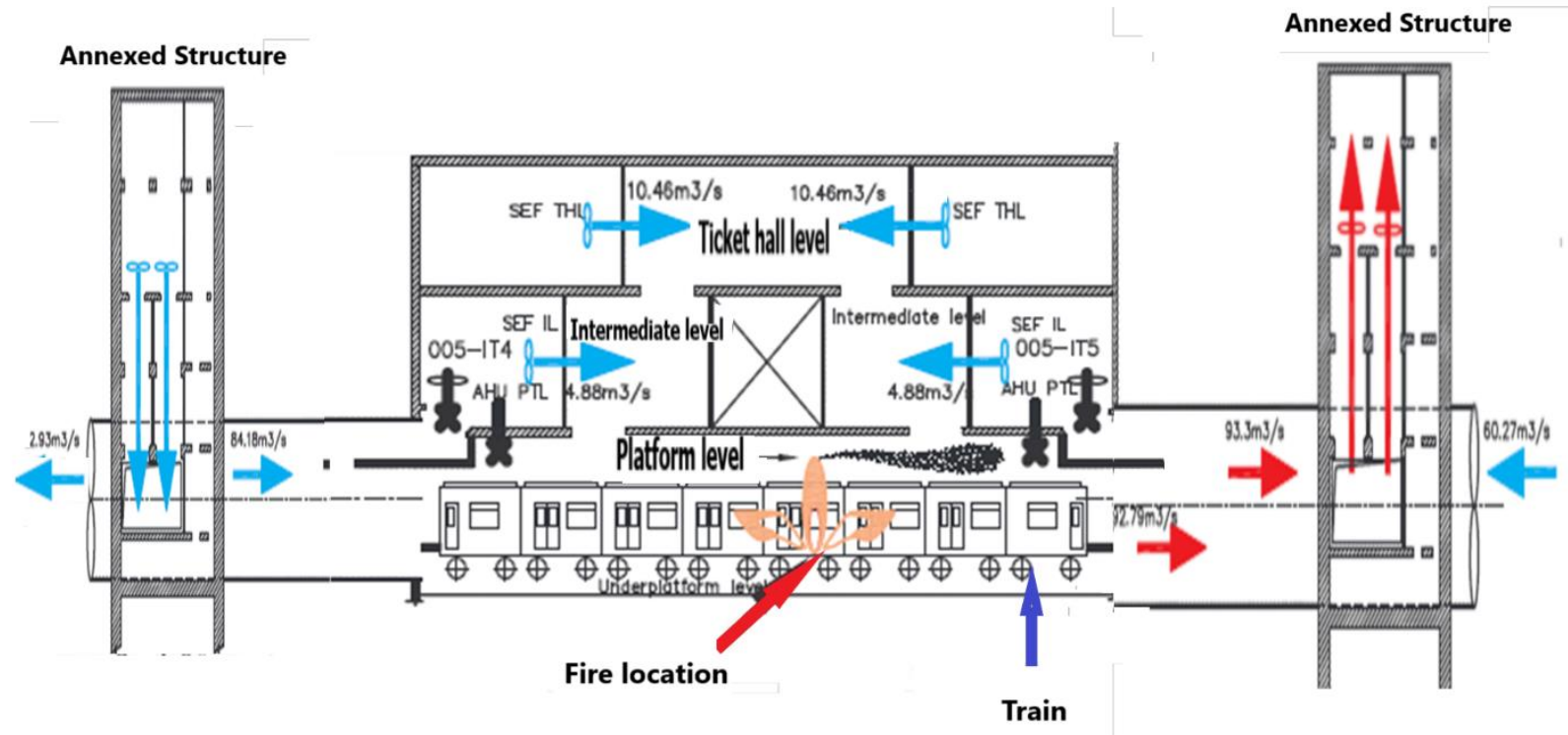

Figure (5) Similar scenario of fire train at platform level.

\section{Computational Domain and analysis case study}

Figure (6) shows a horizontal view underground Cairo metro El-Bohoos station line 2. The designed dimensions are real, the figure contains (platform right and left, train, stairs, seating). Figure (7) shows the cell mesh divided into four cells. Table (1) shows the total number of cell mesh.

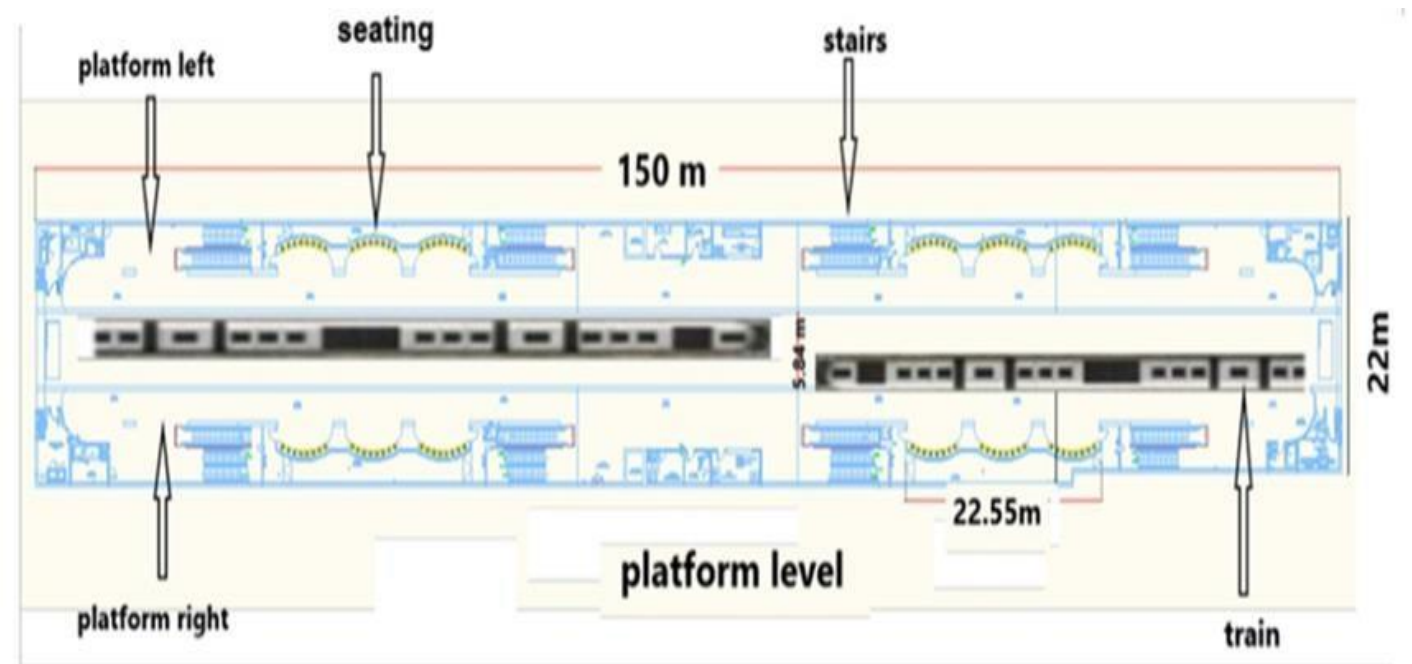

Figure (6) Design underground El-Bohoos metro station. 


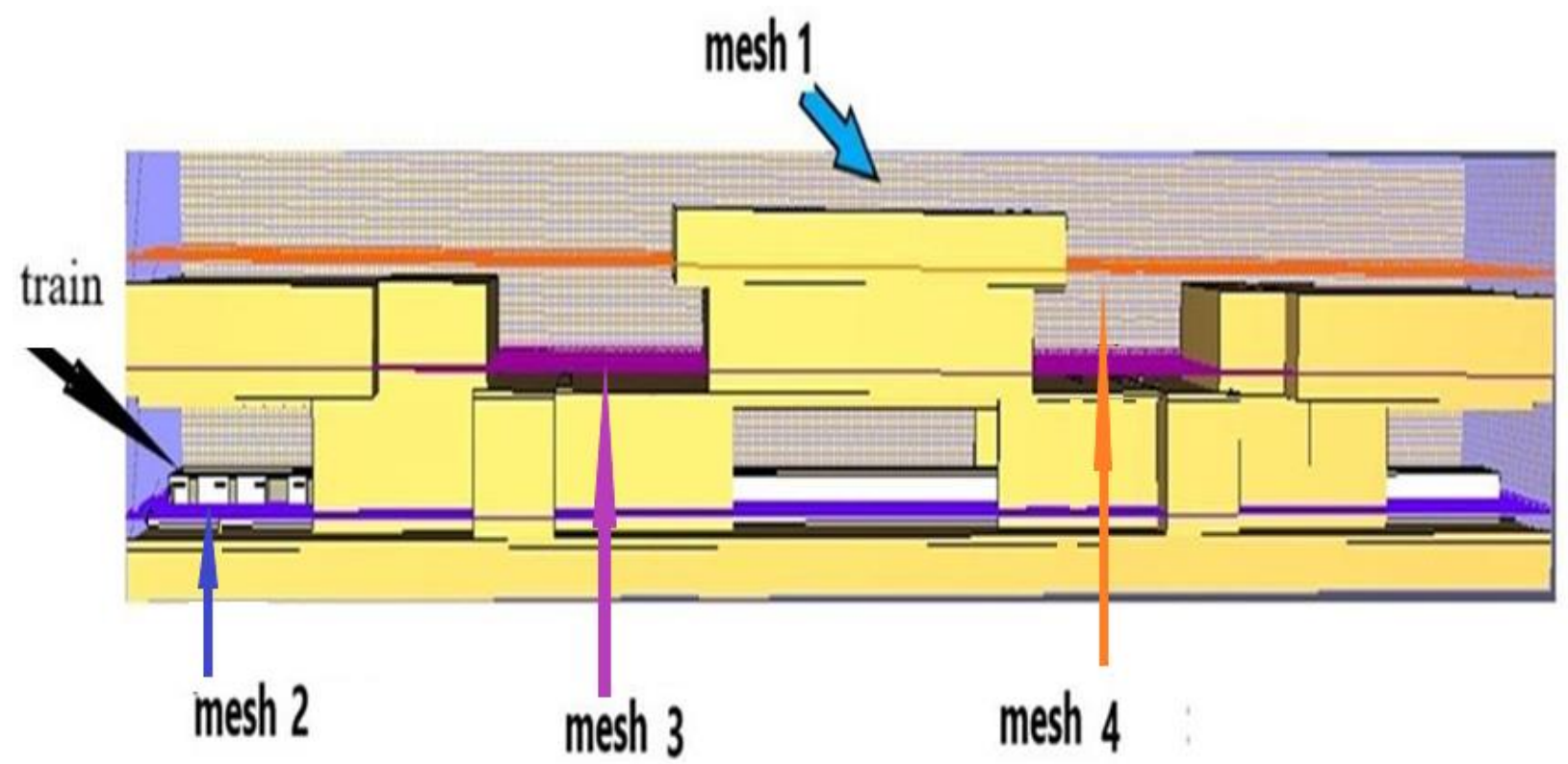

Figure (7) Cell mesh El-Bohoos metro station.

Table (1): Total number of mesh cell

\begin{tabular}{|c|c|c|}
\hline Case & Mesh & Number of mesh cell \\
\hline Case 1 & Mesh 1 & 580800 \\
\hline Case 2 & Mesh 2 & 52800 \\
\hline Case3 & Mesh 3 & 52800 \\
\hline Case4 & Mesh 4 & 52800 \\
\hline Total number of mesh cell & 739200 \\
\hline
\end{tabular}

\subsection{Simulation the model geometry}

As shown in figure (8), the 3D model geometry comprises the following:

- Three levels (platform, intermediate, ticket).

- Ticket window.

- Three-level stairs.

- Exit door.

- Steady Heptane fire. 


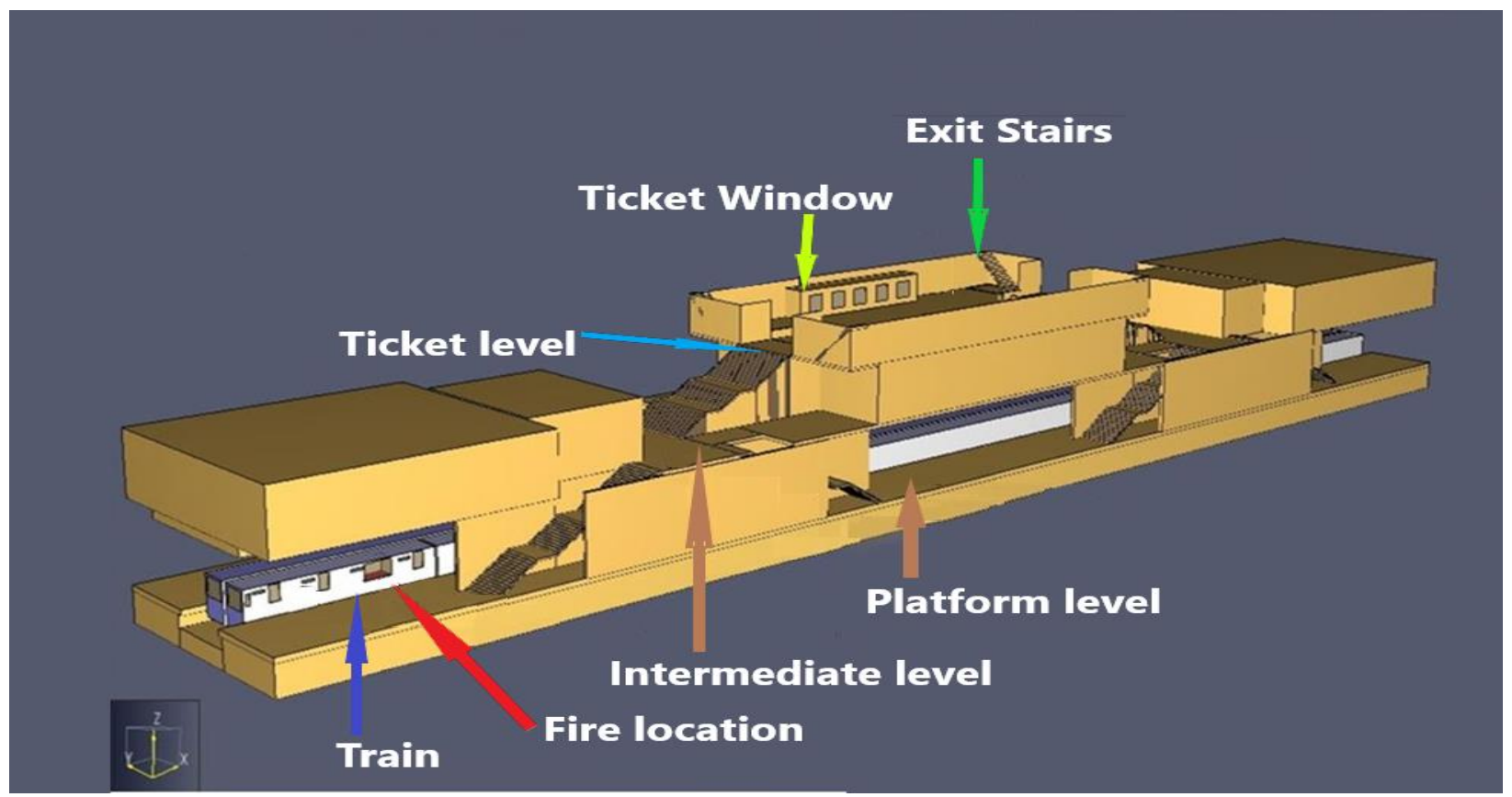

Figure (8) 3D model geometry.

\subsection{Simulation cases of thermocouple distribution}

As shown in figure (9) cases are carried out in this study to measure the temperature in case of fire by using distribution 25 thermocouple along the tunnel station.

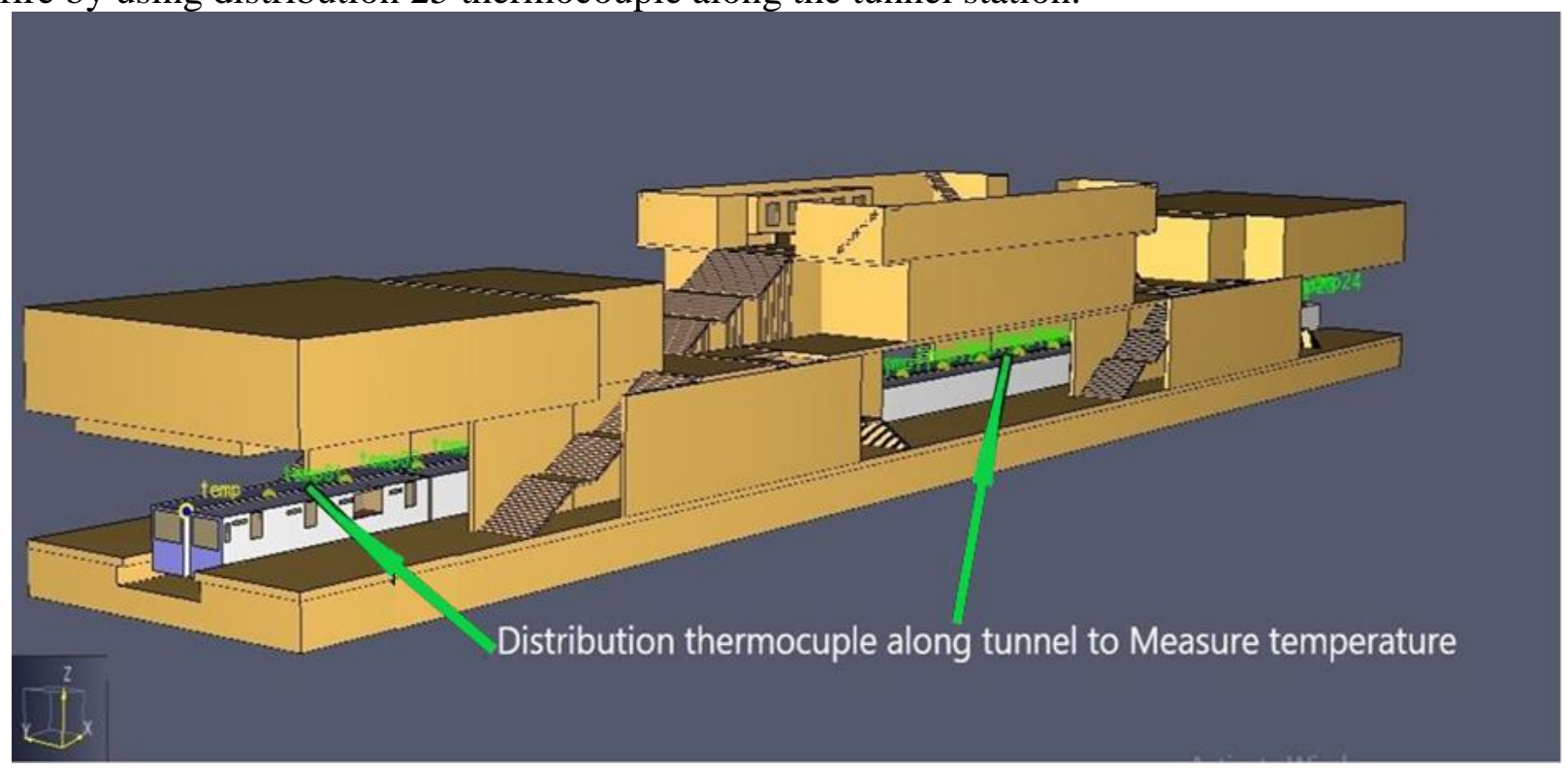

Figure (9) Distribution thermocouple.

\subsection{Simulation cases of evacuation}

To investigate the time needed to evacuate people in case of fire, the average number of passengers was assumed to be 1000 passengers dividing into two trains. Figure (10) shows the results of people evacuation simulation. 

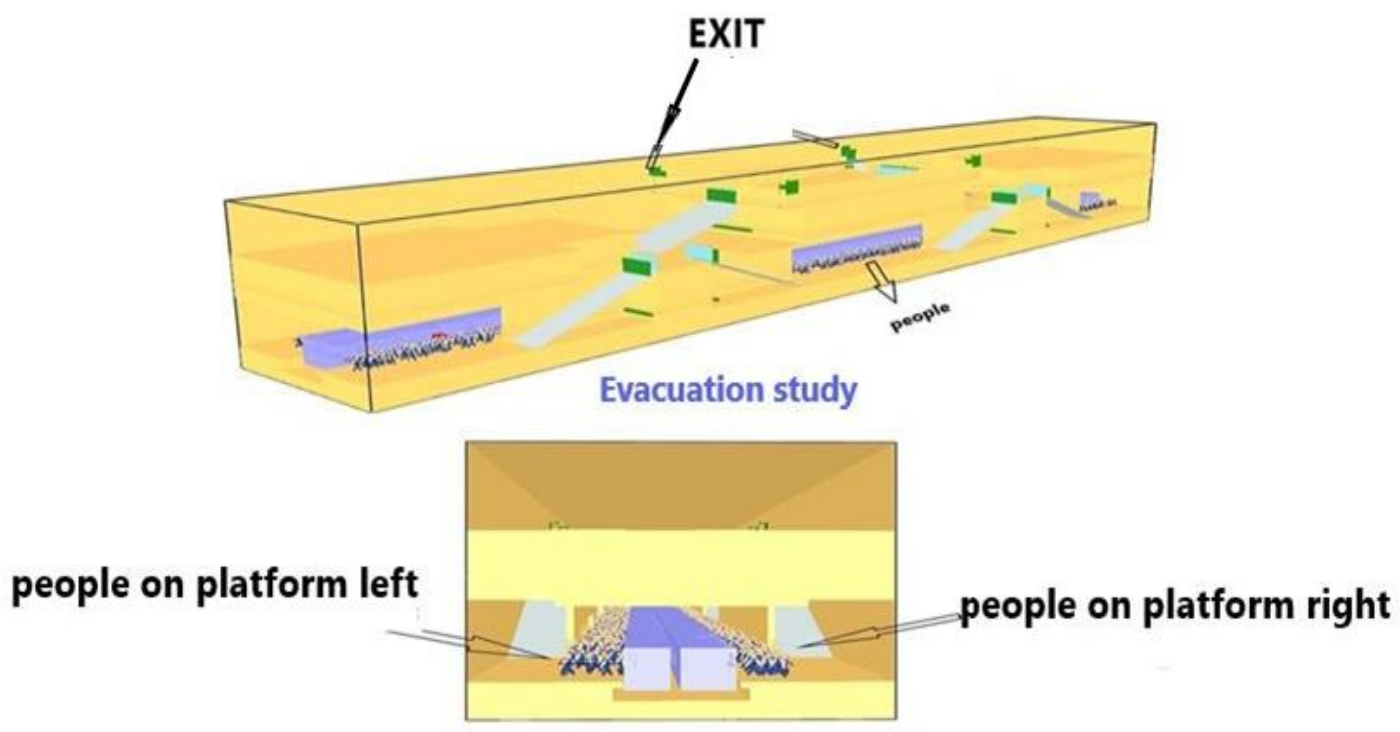

Figure (10) the simulation of people evacuation.

\subsection{Simulation case of control}

As shown in figures (11), (12), and (13) simulation case of control the smoke, the following applied:

- Installing smoke exhaust fan to pull the smoke out by OTE in case of a train fire stops beside the platform level.

- The dimensions of the fans used to control the smoke as shown in table (2).
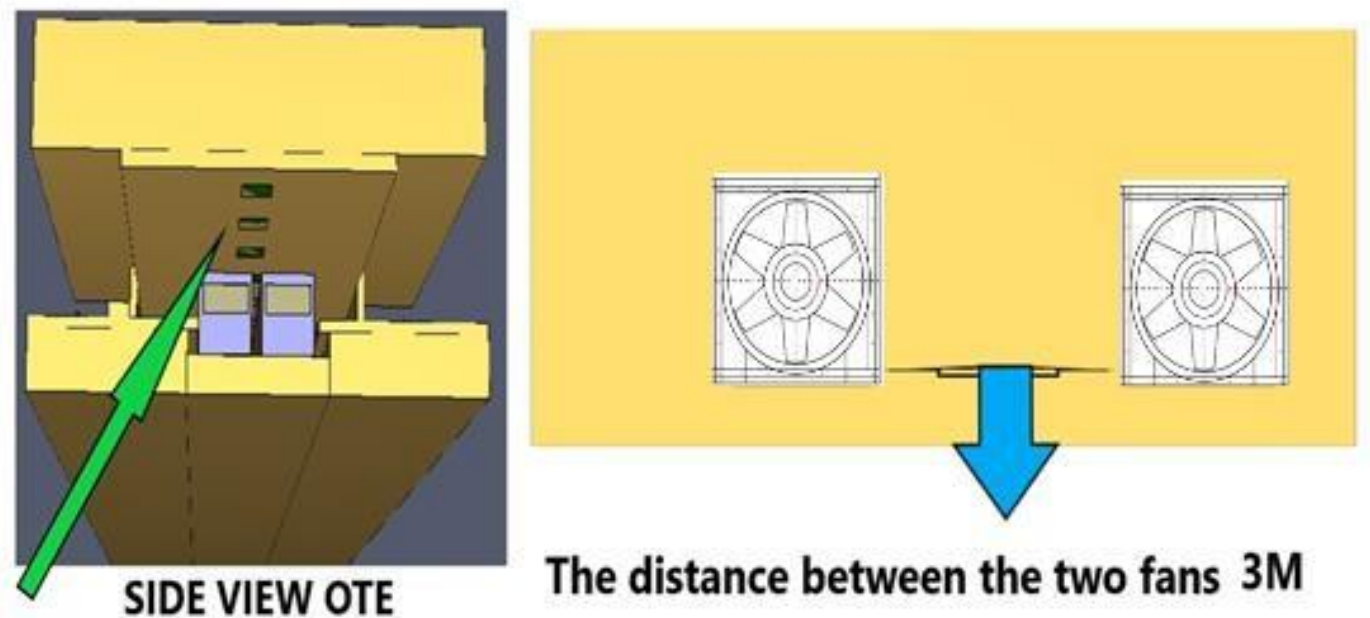

The distance between the two fans $3 \mathrm{M}$

\section{(Overhead Trackway Exhaust)}

Figure (11) Smoke overhead track exhaust (OTE) fans.

Figure (11) shows OTE fans used to pull the smoke out, the distance between two fans along the tunnel (3m). 

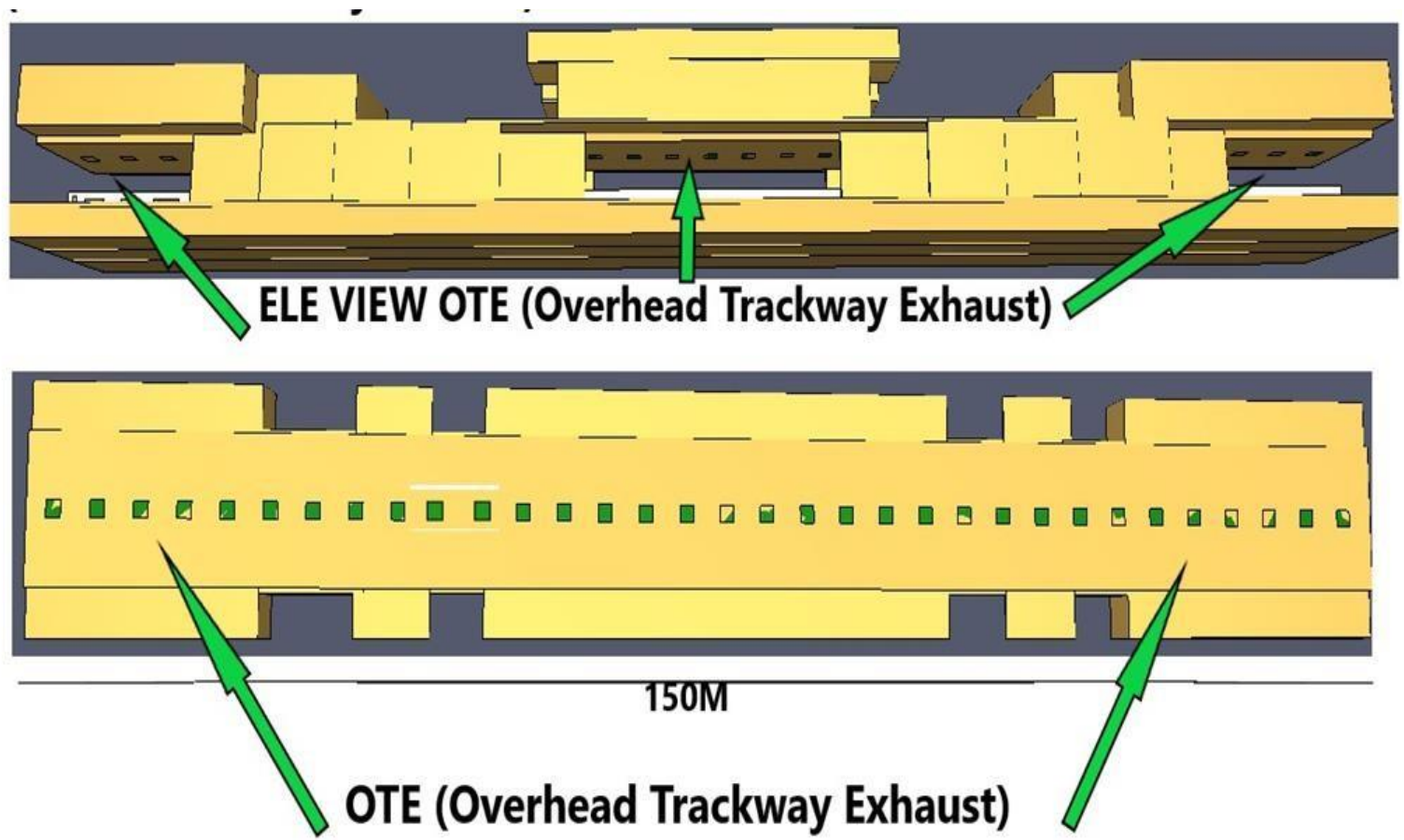

Figure (12) OTE along the tunnel station.

Figure (12), shows OTE along the tunnel station, and a real installation of OTE. Table (2): Smoke fan dimensions (OTE).

\begin{tabular}{|c|c|c|}
\hline 1 & DImension & $(148 * 148 * 58) \mathbf{~ m m}$ \\
\hline 2 & Voltage & $(380-50 \mathrm{hz})$ \\
\hline 3 & Rotating speed & $460 \mathrm{rpm}$ \\
\hline
\end{tabular}

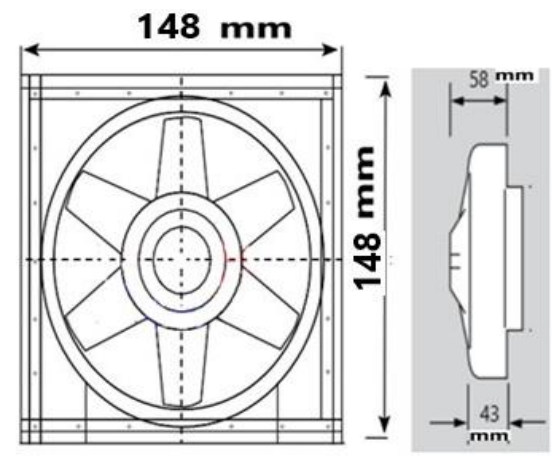

\section{Results and discussions}

\subsection{Evacuation time}

Figure (13) shows simulation evacuation people in case of fire. The people running from platform level to up across the stairs to exit door. The average number of people every train is 500 people. At time $10 \mathrm{sec}$ the people running across the stairs from platform level. At $100 \mathrm{sec}$, most people arrived at the ticket level. At $160 \mathrm{sec}$ the people running to out across exit door and no people on the platform level and intermediate level. At time $190 \mathrm{sec}$ the last person exit from the station. Results by using the FDS program are able to determine the time of the last person leaving the station. 
Evacuation people at time $100 \mathrm{sec}$
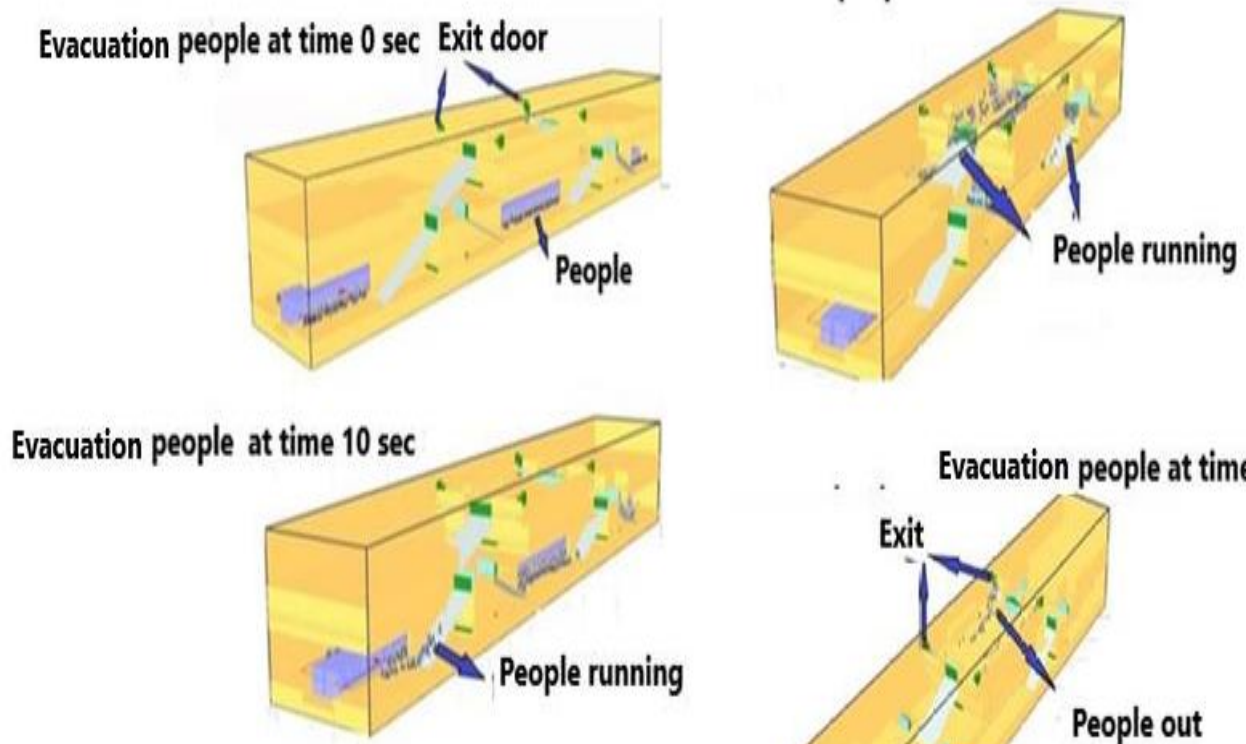

Evacuation people at time $50 \mathrm{sec}$
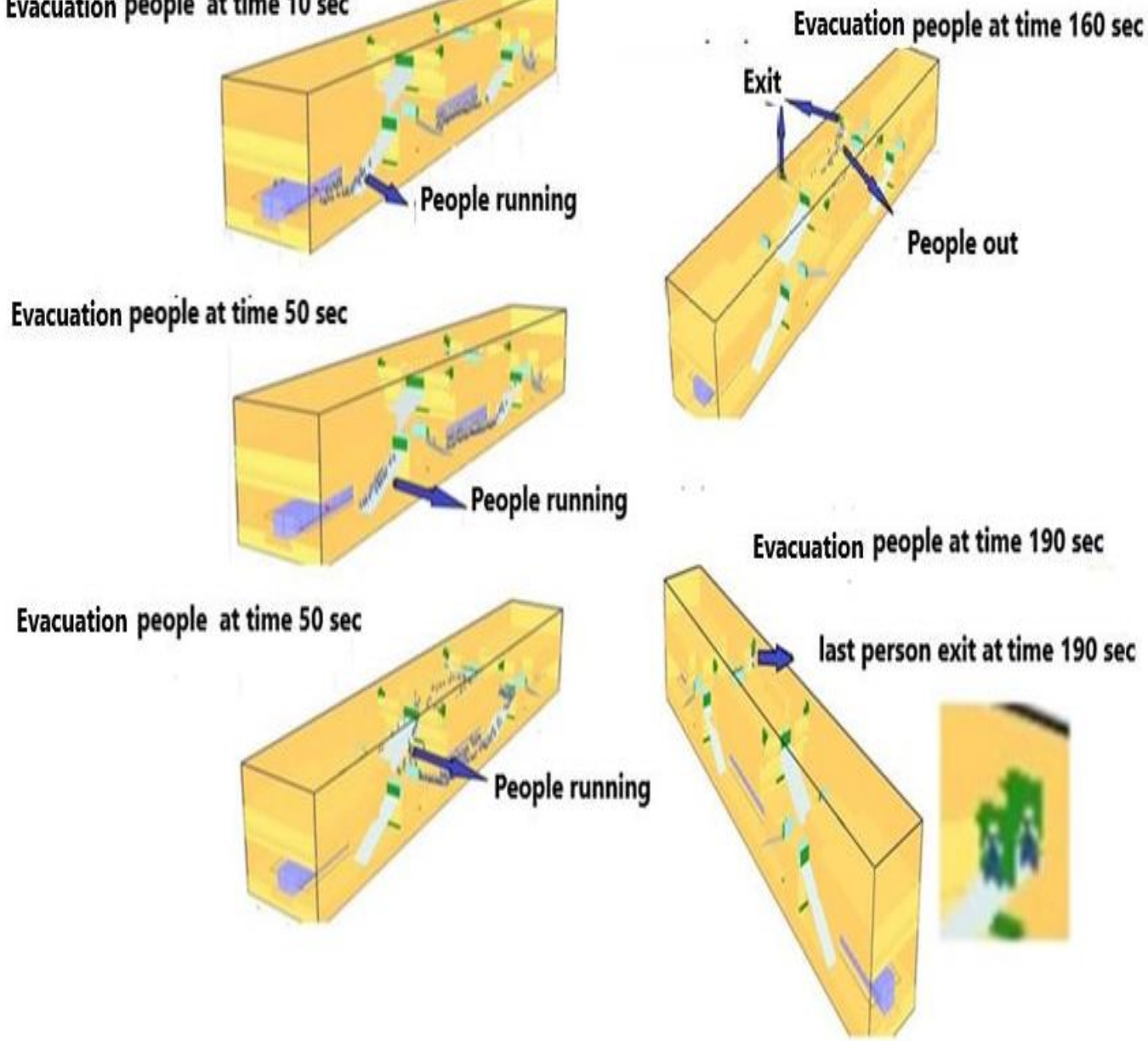

Figure (13) 3D model evacuation of from 0 sec to 190 sec.

\subsection{Comparison of smoke spread before and after control}

Figure (14) shows simulation smoke spread before and after control started from 0 sec to 160 sec. Control the smoke spread by useing overhead track way exhaust to pull the smoke out from the station, this fan construction above the train along the tunnel station. From $0 \mathrm{sec}$ to $60 \mathrm{sec}$ before control, the smoke arrived across the stairs and up, after control no smoke arrived to across the stairs, from $80 \mathrm{sec}$ to $160 \mathrm{sec}$ before control the smoke still fill the station, and after control the overhead track way exhaust prevented the smoke to arrive the stairs. 
Before and after control at time $3 \mathrm{sec}$

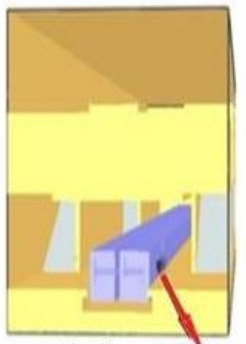

Before Fire source

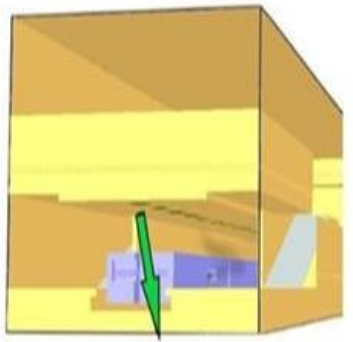

After (OTE)

Before and after control at time $20 \mathrm{sec}$

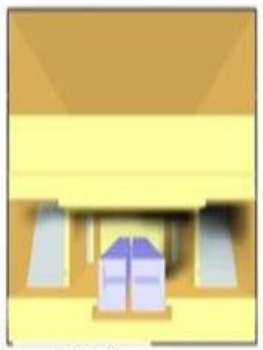

Before

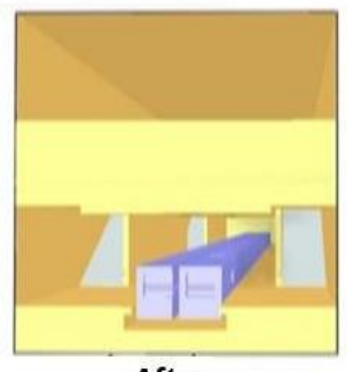

After

Before and after control at time $\mathbf{4 0} \mathrm{sec}$

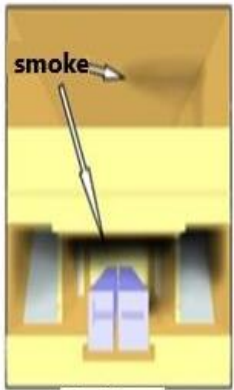

Before

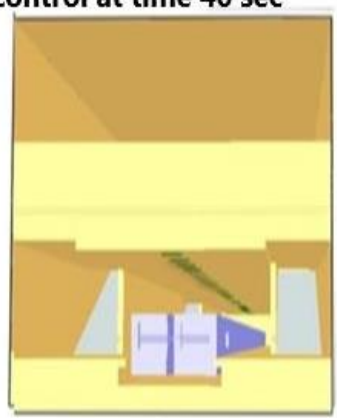

After

Before and after control at time $60 \mathrm{sec}$

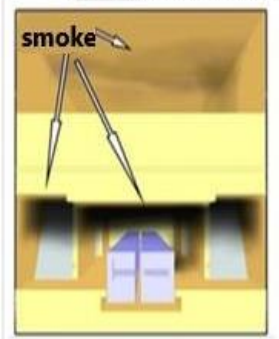

Before

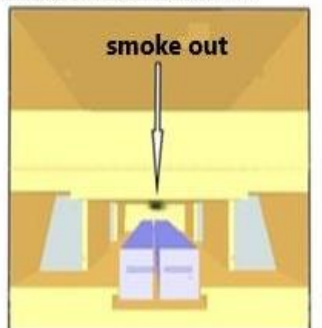

After
Beforeand after control at time $100 \mathrm{sec}$

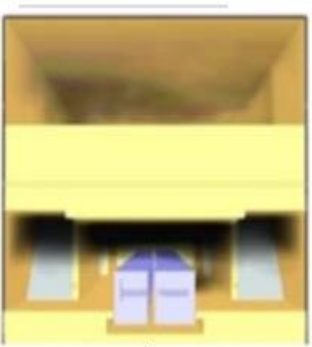

Before

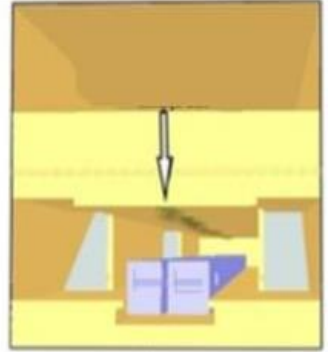

After
Beforeand after control at time $120 \mathrm{sec}$

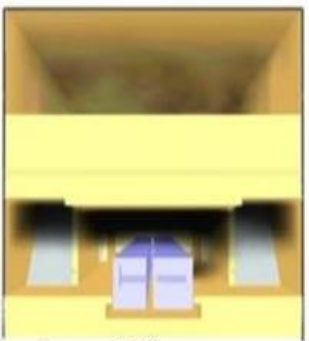

Before

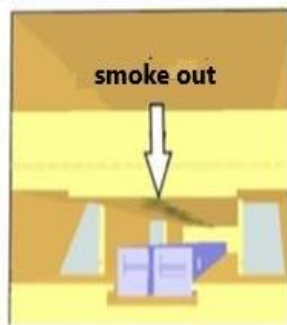

After
Before and after control at time $140 \mathrm{sec}$

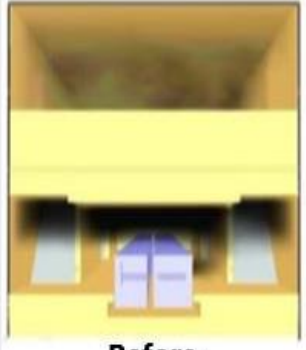

Before

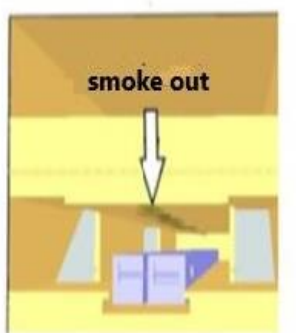

After
Before and after control at time $160 \mathrm{sec}$

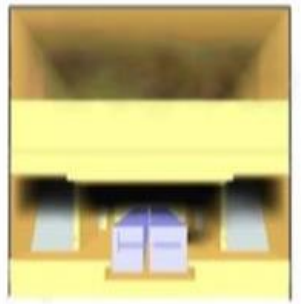

Before

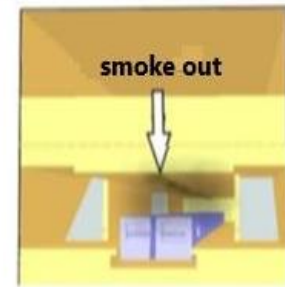

After

Figure (14) Comparison of smoke spreading before and after control.

As shown in figure (15) the time from $180 \mathrm{sec}$ to $300 \mathrm{sec}$ before control the smoke fills all the station, after control, the smoke spread gradually. From the results of case (4-1) the last person leaving the station at time $190 \mathrm{sec}$. The results of the overhead track way exhaust helped people escape in a clear vision and reduce the occurrence of suffocation. From the previous studies, an arson occurred at Daegu Jungangno subway station, and the fire spread over six trains and killed 
192 passengers in February 2003 [11]. Investigations showed that the ventilation system supplying fresh air into the station failed to be switched to an emergency extraction system to remove smoke from the station. The most immediate threat to passengers' lives is not direct exposure to fire, but smoke disturbance and smoke inhalation because it decreases the visibility of the escape route and contains hot air and toxic gases.

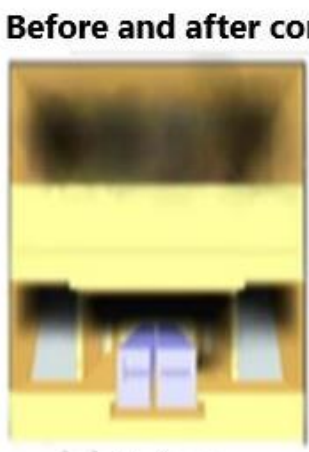

Before

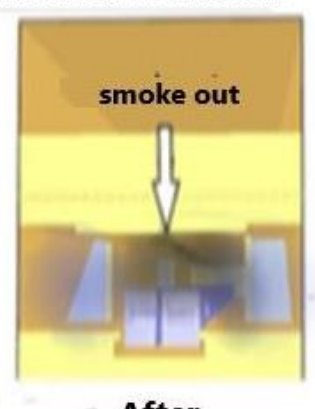

After

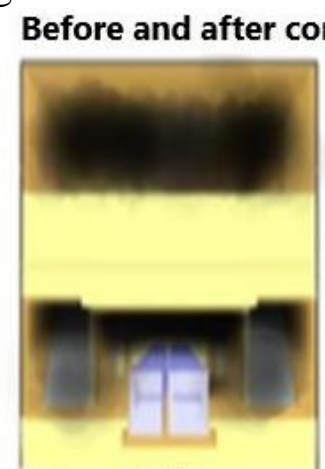

Before

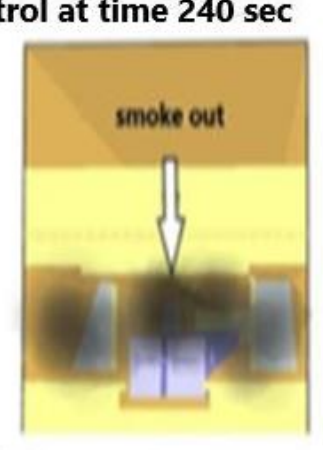

After

\section{Before and after control at time $200 \mathrm{sec}$}

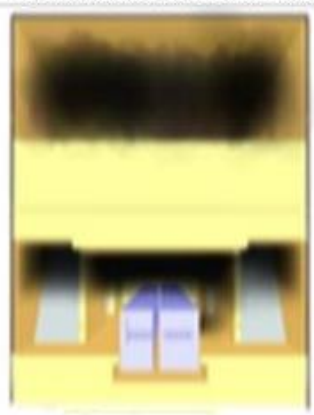

Before

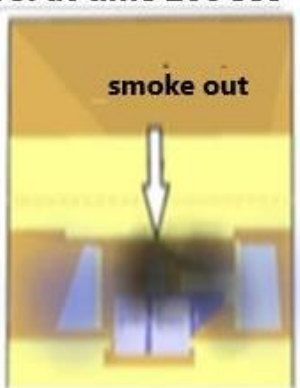

After

\section{Before and after control at time $260 \mathrm{sec}$}

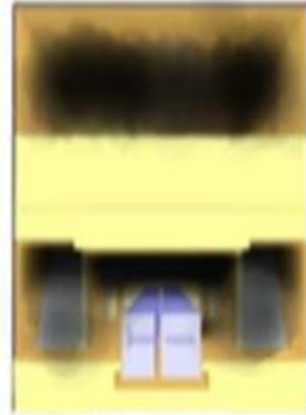

Before

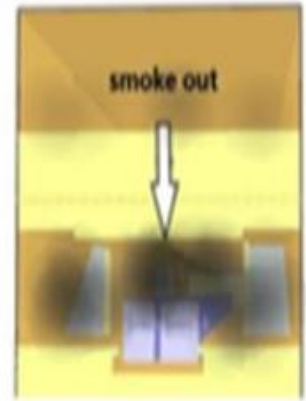

After
Before and after control at time $220 \mathrm{sec}$

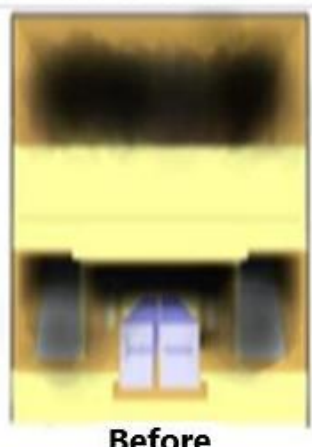

Before

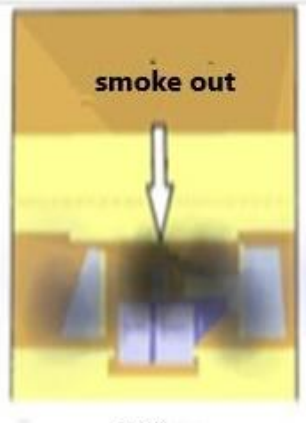

After

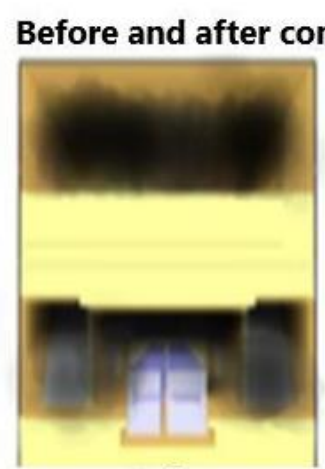

Before

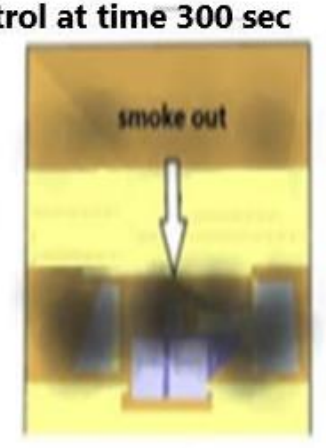

After

Figure (15) Comparison of smoke spread before and after control.

\subsection{Comparison results of temperature before and after control.}

Figure (16) shows comparison the results of temperature curves before and after control, by using the thermocouple to measure the temperature, installed at dimension $(y=11 \mathrm{~m}, \mathrm{z}=5.35 \mathrm{~m})$ along the tunnel station, the curve relation between (temperature \&time), before control the curve started from $200{ }^{\circ} \mathrm{C}$ and change with time to up, after control the curve started from 200 
${ }^{\circ} \mathrm{C}$ and down stable with time. Results that by using OTE able to extraction the smoke out and helps to reduce the ambient temperature during the escape.
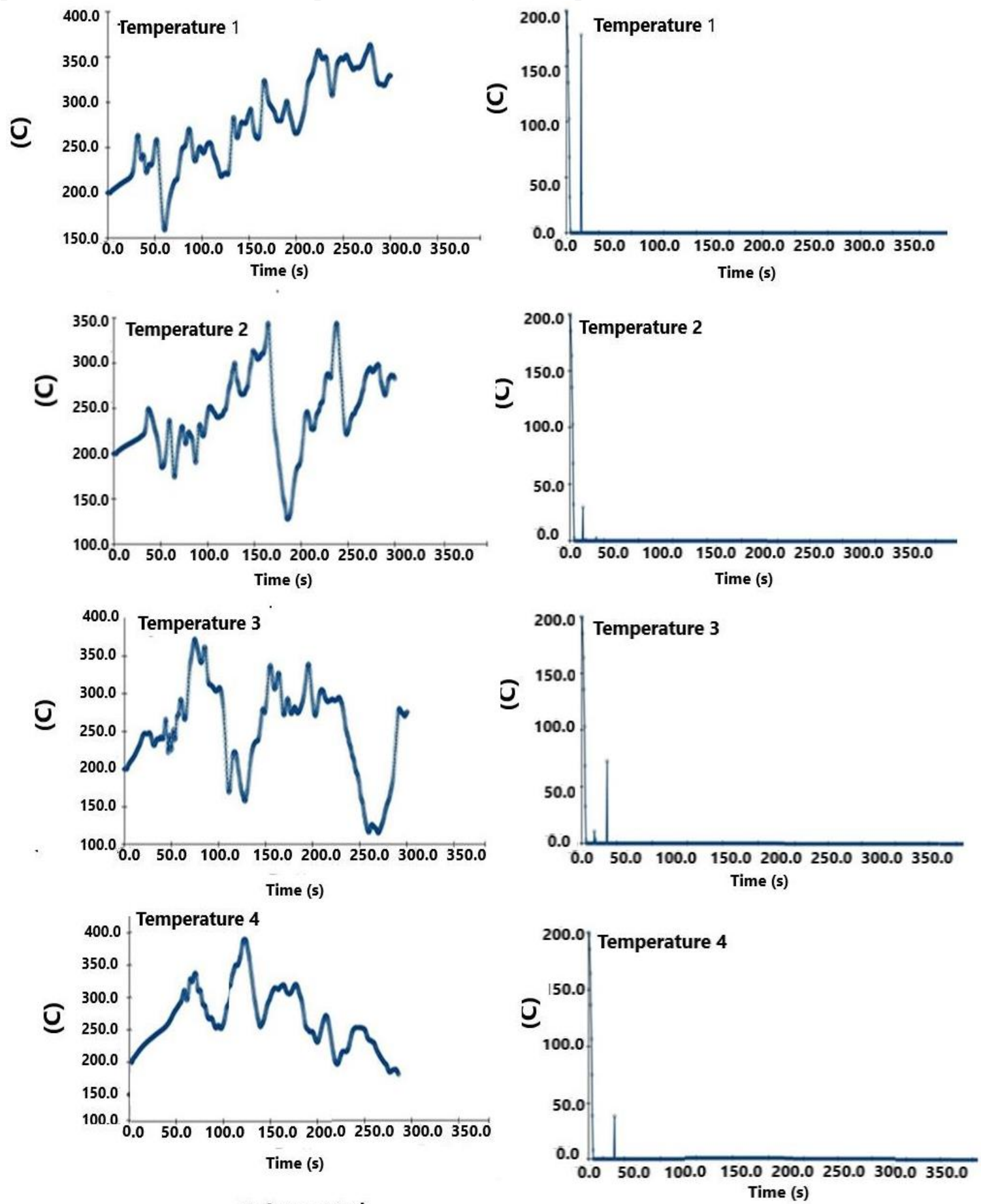

Before control

\section{After control}

Figure (16) Result of temperature curves before and after control.

\subsection{Comparison Results of (Heat Release Rate, Radiation Loses)}

Figures (17) and (18) show a comparison of the results (heat release rate (HRR), radiation losses (RAD)) before and after control. The curves relation between (KW, Time). 

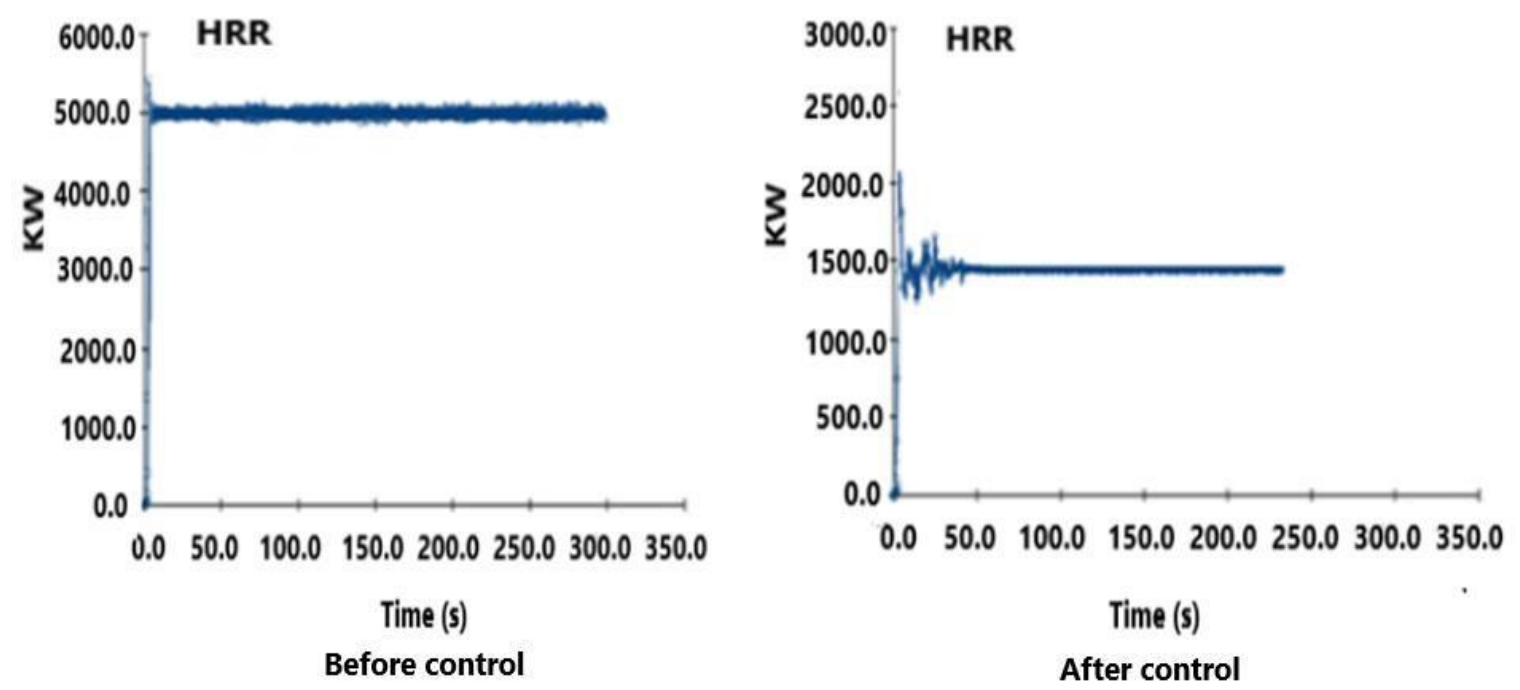

Figure (17) Result of heat release rate (HRR) curve.

Figure (17) shows the heat release rate, before control the curve started from $0 \mathrm{~kW}$ and up to more $5000 \mathrm{KW}$ and down stable at $5000 \mathrm{KW}$ with time, after control the curve starts from $0 \mathrm{KW}$ and up to $2000 \mathrm{KW}$ and down to $1500 \mathrm{~kW}$ stable with time Results that there is a difference before and after control nearly $3500 \mathrm{KW}$.
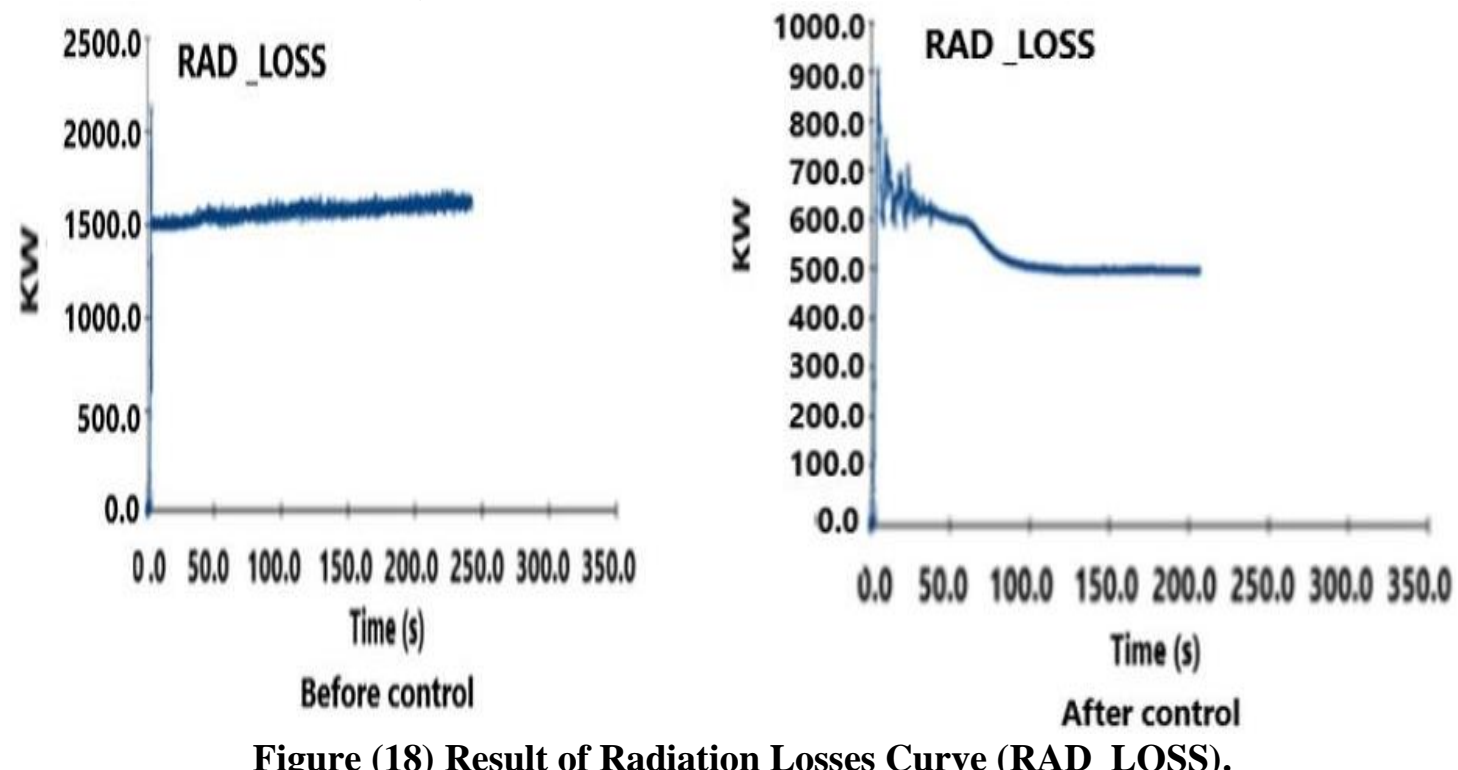

Figure (18) Result of Radiation Losses Curve (RAD_LOSS).

Figure (18) shows Radiation Losses (RAD_LOSS), before control the curve started from $0 \mathrm{~kW}$ and up to more $2000 \mathrm{~kW}$ and down stable at $1500 \mathrm{~kW}$ with time, after control the curve starts from $0 \mathrm{~kW}$ and up to $900 \mathrm{~kW}$ and down to $500 \mathrm{~kW}$ stable with time. Results that there is a difference before and after control nearly $1500 \mathrm{~kW}$.

\section{Conclusions and suggested future work}

The temperature comparisons in the cases before and after applying the smoke-control showed that without smoke-control, the resultant curves were increasing with time, while after applying the control, the resultant curves started high then suddenly decreased to stabilize at low values. 
The utilization of OTE fans for pulling the smoke out of the station resulted in reducing air temperature and helped people to escape in a low-temperature and visible-clear atmosphere.

According to the calculated evacuation-time for the last person exiting the station (190 sec), the suffocation cases during people evacuation before and after applying smoke-control were compared. The results showed that before applying the control, people suffocated to death due to the smoke-accumulation, while after applying the control, people escaped with a clearer vision and lower suffocation.

\section{References}

[1] Rie .DH. Hwang MW. Kim .SJ. Yoon .SW. Ko .JW. Kim. HY, (2006). Astudy of optimal vent mode for the smoke control of subway station fire. Tunnelling and underground space technology, 21: 300-301

[2] Park. W.H. Kim .DH.Chang .HC, (2006). Numerical predictions of smoke movement in a subway station under ventilation. Tunnelling and underground space technology, 21: 304.

[3] McGrattan. KB.Hostikka .S. Floyd .JE ,(2010). Fire Dynamics Simulator (Version 5), user's guide. NIST special publication. National institute of standards and technology

[4] Chen.F.L.Guo. S.C. Chuay. H.Y. Chien. S.W, 2003. Smoke control of fires in subway station. Theoretical and computational fluid dynamics 16, 349-368

[5] Yuan FD.You .SJ,(2007). Simulation and optimization of the ventilation for subway sideplatform. Tunneling and underground space technology , 22: 474-482

[6] Jae .SR. Hong .SR. Sung .WY ,2010). The effect of PSD on life safety in subway station fire. Journal of mechanical science and technology,24: 937942

[7] Roh. JS. Ryou. HS. Yoon. SW, 2010. The effect of PSD on life safety in subway station fire. Journal of Mechanical Science and Technology 24 (4), 937-942.

[8] Hu .LH. Huo .R. Wang. HB. Yang RX .(2007). Experimental and numerical studies on longitudinal smoke temperature distribution upstream and downstream from the fire in a road tunnel. Journal of Fire Sciences, 25: 2343.

[9] Jin, T. Yamada T, 1985. Irritating effects from fire smoke on visibility. Fire Science and Technology 5 (1), 79-90.

[10] 51M-FF-RP-0146-1.0. Fire Scenarios Description

[11] Yamada. T. Pyo. JB, 2003. Outline of subway train fire in daegu jungangno station. Kasai $53(2), 1-8$. 